\title{
Hares in the long grass: increased aircraft related mortality of the Irish hare (Lepus timidus hibernicus) over a 30-year period at Ireland's largest civil airport
}

\author{
Samantha Ball ${ }^{1,2}$ (1) $\cdot$ Fidelma Butler ${ }^{1} \cdot$ Anthony Caravaggi $^{3} \cdot$ Neil E. Coughlan $^{1,4} \cdot$ Gerry Keogh $^{2}$. \\ Michael J. A. O'Callaghan ${ }^{5} \cdot$ Ricky Whelan $^{6}$. Thomas C. Kelly ${ }^{1,2}$
}

Received: 10 July 2020 / Revised: 8 July 2021 / Accepted: 22 July 2021 / Published online: 10 August 2021

(C) The Author(s) 2021

\begin{abstract}
Collisions between wildlife and aircraft are a serious and growing threat to aviation safety. Understanding the frequency of these collisions, the identity of species involved, and the potential damage that can be inflicted on to aircraft aid mitigation efforts by airfield managers. A record of all animal carcasses recovered from Dublin International Airport, Ireland's largest civil aviation airport, has been maintained since 1990 where strikes with the endemic Irish hare (Lepus timidus hibernicus), a protected subspecies of mountain hare, are of particular concern despite substantial management efforts from the airfield authority. The first strike event with a hare was recorded in 1997, and strike events have substantially increased since then, with a sharp increase recorded in 2011. Over a 30-year period, a total of 320 strike events with the Irish hare have been recorded at the airfield. To date, no strike event with a hare has resulted in damage to an aircraft. However, carcasses can present as a major attraction to avian scavenger species in addition to posing as a risk of causing foreign object damage in the event of an undetected carcass. Hare strikes are discussed in the context of the rate of civil aircraft movements, possible direct and indirect damage to aircraft, and airfield wildlife hazard management. Here, we demonstrate that not only are strike events increasing by $14 \%$ on an annual basis, but that the kinetic energy of such an event has the potential to cause significant damage to an aircraft.
\end{abstract}

Keywords Airfield management · Air safety · Human-wildlife conflict · Foreign Object Damage (FOD) · Scavenger guild · Wildlife strike $\cdot$ Wildlife hazard management

This article is part of the Topical Collection on Road Ecology Guest Editor: Marcello D'Amico

Samantha Ball

Samantha.ball@ucc.ie

1 School of Biological, Earth and Environmental Science, Distillery Fields, University College Cork, Cork T23 TK30, Ireland

2 Dublin Airport Authority, Airport Fire \& Rescue Service, Dublin K67 CX65, Ireland

3 School of Applied Sciences, University of South Wales, 9 Graig Fach, Glyntaff, Pontypridd CF37 4BB, UK

4 School of Biological Sciences, Queen's University Belfast, 19 Chlorine Gardens, Belfast BT9 5DL, UK

5 Department of Applied Mathematics, School of Mathematical Sciences, University College Cork, Cork T12 XF62, Ireland

6 BirdWatch Ireland, Bullford Business Campus, Kilcoole A63 RW83, Greystones, Wicklow, Ireland

\section{Introduction}

Air travel is vital to our global economy. In 2018 alone, over 4.3 billion passengers globally were carried by aircraft and revenues for the airline industry exceeded US\$812 billion (IATA 2019). There are over 40,000 airports globally according to the International Civil Aviation Organisation (ICAO), many with expanses of semi-natural grassland often providing unique and productive habitat (Hauptfleisch and Avenant 2015) that is attractive to a range of wildlife taxa. The presence of wildlife on airfields can be hazardous to aviation, resulting in collisions between wildlife and aircraft, henceforth referred to as 'strikes' e.g. (McKee et al. 2016). A sustained increase in the rate of collisions between wildlife and aircraft is considered a serious and growing threat to aviation safety, globally (e.g. Metz et al. 2020; Ball et al. 2021). 
Whilst not all wildlife strikes result in damage, some wildlife strikes have led to human fatalities and substantial economic losses for the aviation industry (see https://avisure. com/incident-database/). For example, bird strikes are estimated to cost upwards of US $\$ 1.2$ billion to the global civil aviation industry, annually (Allan 2002). However, whilst the majority of wildlife strikes involve bird species (e.g. 94\% of strikes in the USA; Dolbeer and Begier 2021), many volant (bats) and terrestrial mammal species are also struck (e.g. Crain et al. 2015; Kelly et al. 2017; Ball et al. 2021), as well as reptiles, amphibians and even insects (e.g. Noaves et al. 2016; House et al. 2020). Strikes involving mammals have been estimated to cost over US $\$ 103$ million in the USA alone (Ball et al. 2021) with some mammal groups (e.g. deer, carnivores) being particularly responsible for costly damages (Biondi et al. 2011; Crain et al. 2015). Additionally, smaller mammals can attract scavenger and predatory species, introducing secondary strike risk (Pennell et al. 2016) and additional ecological complexity to management decisions (Washburn and Seamans 2013; Hauptfleisch and Avenant 2015). Hence, here we present a case study of mammal strikes, focusing on the Irish hare (Lepus timidus hibernicus, Bell 1837) at Ireland's largest civil airport—Dublin International Airport.

The endemic Irish hare (Lepus timidus hibernicus), a subspecies of the mountain hare (Lepus timidus, Linnaeus 1758), resides in and around the grasslands at the airfield at Dublin. This subspecies is considered to be a priority species for conservation action in Ireland (Reid et al. 2010; Caravaggi et al. 2017). However, since 1997, strike events with the Irish hare have been recorded annually. Indeed, despite foxes (Vulpes vulpes), hedgehogs (Erinaceus europaeus), rabbits (Oryctolagus cuniculus) and rats (Rattus norvegicus) also being recorded at the airfield, there has only been the occasional recorded incident with these species (Bolger and Kelly 2008), as well as the occasional bat strike (Kelly et al. 2017). Wildlife hazard management actions for mitigation of hare strikes at Dublin Airport include deployment of scaring techniques (e.g. pistol), licensed trapping and translocation, and, subject to safety considerations, a licenced cull. Notably, since 2014, more than 650 hares have been removed from Dublin under licence, whilst a minimum of an additional 191 were killed by aircraft. Given the conservation status of this subspecies, the Dublin Airport Authority is actively exploring new, non-lethal technological solutions for hare population management. Hare population densities are substantially higher within the airfield environment for both Dublin and Belfast International airports, at up to 30 hares $/ \mathrm{km}^{2}$, than elsewhere in Ireland (up to 3.19 hares $/ \mathrm{km}^{2}$; McGowan et al. 2019). Hence, the strike events are highly unlikely to have population-level impacts and are of little concern with regards to the conservation of the species.
The airfield at Dublin Airport contains approximately 680 ha of grassland. Typical of many airfields located within the temperate zone of the Northern Hemisphere, these grasslands have been maintained on the principles of a 'long grass' management policy since the 1980s (Bolger and Kelly 2008; UKCAA Safety Regulation Group CAP 2008) and consist of a blend of tall fescue (Festuca arundinacea) and Italian ryegrass (Lolium multiflorum). The presence of long grass at the airfield successfully deters avian species. As hares are present both airside and landside at Dublin, it is unknown if the presence of long grass impacts on the hare population or indeed acts as an attractant. However, airfields elsewhere in Europe have consequently reported long grass $(<20 \mathrm{~cm})$ as a wildlife attractant for mammal species, such as hares, by providing suitable habitat and shelter (Ball et al. Unpublished data), demonstrating the complexity of wildlife management in sensitive airfield environments.

Here, we report on the number of hare strikes recorded at Dublin Airport over the 30-year period from 1990-2019. Hare strikes are of great concern to air safety at Dublin Airport, not only in their own right, but also due to the secondary risks associated with a strike event. These include the luring of scavenger species to the site of a strike and the ingestion of an undetected carcass into an engine as foreign object damage (FOD). Specifically, airfield operators have a legal responsibility to reduce wildlife hazard at airfields (Mendonca et al. 2017) and are liable for any damages inflicted. For example, in 2005, Air France was awarded $€ 4$ million after a bird strike incident induced by gulls scavenging from an undetected hedgehog carcass resulted in engine damage (Dale 2009). Whilst, in the present study, we report only on instances from one airfield, it is important to note that strikes with the Lagomorpha are not unique to Dublin or indeed to Ireland. Other European countries frequently report strike events with species of this taxon (e.g. Kitowski 2016), as do Australia (ATSB 2019) and North America (Canada and the USA, e.g. Dolbeer and Begier 2021), with strikes also reported in countries in Africa and Central America (Ball et al. 2021).

\section{Materials and methods}

\section{Carcass collection}

Wildlife strike events and recovered carcasses from Dublin Airport (Airport Reference Point (ARP): $532517 \mathrm{~N}$ $0061612 \mathrm{~W}$ ) have been recorded since 1990. Carcasses were collected from runways following reported strikes or during mandatory routine inspections (i.e. the 'recorded check'), to prevent against foreign object damage (FOD) to aircraft by debris. Any debris, including that composed of organic material, is removed from the manoeuvring areas 
and the conditions surrounding the strike incident recorded (e.g. date, location). Some strike incidents involved multiple individuals but were recorded as a single strike event. Carcasses resulting from collisions with service vehicles were appropriately labelled and subsequently excluded from analysis. Post-collection, all carcasses were immediately placed in cold storage $\left(-20^{\circ} \mathrm{C}\right)$ until examination at a later date. Morphological indicators were used to identify specimens to species level via consultation of Harris and Yalden (2008). A total of 54 carcasses had been retained by the airport and, where possible, specimens were aged, sexed and weighed (e.g. Ball et al. 2020).

\section{Estimation of the rate of hare strikes and potential impact damage}

Incident rates of the Irish hare were calculated as the annual number of strikes per 10,000 aircraft movements (one movement $=$ one landing or one take-off) between 1990 and 2019. Bespoke annual aircraft movement data were obtained from the Irish Aviation Authority (IAA) and Dublin Airport Authority (DAA) records. There have been no damaging strike events with the Irish hare to an aircraft's fuselage, engines, undercarriage or otherwise. The Boeing 737-800 and the Airbus A320 have the greatest number of movements at Dublin Airport ( $60 \%$ of all aircraft movements; Dublin Airport Authority, Unpublished Data). The potential impact damage for these two aircraft was calculated in terms of kinetic energy (KE; joules) and converted to the impact descriptor of foot-pounds (ft-lbs), where body of mass (m), in kilograms, moving with speed (v), in meters per second, is expressed as $\mathrm{KE}=1 / 2 \mathrm{mv}^{2}$ (see Kelly et al. 2016, 2017). We assume maximum take-off or landing speeds for aircraft (A320 at $268.6 \mathrm{kph}$; B737 at $260.1 \mathrm{kph}$, from Kelly et al. 2017) and take the maximum mass for an adult Irish hare from previous strike events (Online Resource 1), at $3.8 \mathrm{~kg}$ (Table 1), as an estimate of the maximum potential damage that a hare strike could possibly inflict on an aircraft during a typical manoeuvre at Dublin Airport. The kinetic energy of a strike event with a hare of low (juvenile, $1.3 \mathrm{~kg}$ ), medium $(2.2 \mathrm{~kg})$ and high (adult female, $3.8 \mathrm{~kg}$ ) mass for speeds ranging from $1 \mathrm{~m} / \mathrm{s}$ to the take-off speed of the faster aircraft (A320) at $75 \mathrm{~m} / \mathrm{s}$ was calculated. Respective masses were used from hares involved in strike events at the airfield, from intact carcasses ( $n=14$, Online Resource 1). The mean of these weights was used for the medium weight. Under the same conditions, we also calculate the kinetic energy of a strike event with two species which scavenge and predate on hares and are also present at the airfield, namely, the red fox and the common buzzard (Buteo buteo). Equally, in obtaining these estimates, we have ignored the secondary effects of the speed of the fauna as they are negligible when compared to that of an aircraft (Metz et al. 2020).
Table 1 Kinetic Energies of Irish hare (Lepus timidus hibernicus), red fox (Vulpes vulpes) and common buzzard (Buteo buteo) collisions with aircraft. Kinetic energies are calculated using the maximum mass of an adult Irish hare and the maximum speeds observed during take-off or landing of aircraft

\begin{tabular}{lllll}
\hline Species & Aircraft & $\begin{array}{l}\text { Maximum } \\
\text { mass } \\
(\mathrm{kg})\end{array}$ & $\begin{array}{l}\text { Max speed } \\
\mathrm{m} \mathrm{s}^{-1}(\mathrm{kph})\end{array}$ & $\begin{array}{l}\text { Kinetic energy } \\
\text { Joules (ft-lbs) }\end{array}$ \\
\hline Irish hare & A320 & 3.8 & $74.61(268.6)$ & $10,576(7,800)$ \\
& B737-800 & 3.8 & $72.02(260.1)$ & $9,855(7,269)$ \\
Red Fox & A320 & $9.3^{1}$ & $74.61(268.6)$ & $25,885(19,092)$ \\
& B737-800 & 9.3 & $72.02(260.1)$ & $24,119(17,789)$ \\
Buzzard & A320 & $1.4^{2}$ & $74.61(268.6)$ & $3,897(2,874)$ \\
& B737-800 & 1.4 & $72.02(260.1)$ & $3,631(2,677)$ \\
\hline
\end{tabular}

${ }^{1}$ Harris and Yalden (2008)

${ }^{2}$ Demongin (2016)

\section{Statistical analysis}

All statistical analysis was carried out in programme $\mathrm{R} \mathrm{v}$ 4.0.4. As data spanned over a 30 -year period, we divided study periods into three, 10-year intervals (1990-1999, 2000-2009 and 2010-2019). To determine if there was a significant difference in the median number of strikes between study intervals, we used the Kruskal-Wallis test for non-parametric data and used the 'Dunn's test' for further post hoc analysis between intervals with a 'Benjamini-Hochberg' $p$-value correction (Benjamini and Hochberg 1995) to allow for multiple comparisons. To evaluate the trend (\% increase) in the number of strike events over time (years) with hares at Dublin Airport, we used general linear modelling (GLM), with a 'quasiPoisson' error structure, implemented within the 'Ime4' package (Bates et al. 2015). To investigate the relationship between the number of strike incidents and aircraft movements over time, we used a generalised linear mixed model, with year fitted as a random effect to account for temporal variation, with a 'Poisson' error structure. Temporal strike data (season, month, time) were available for 2012-2019. To investigate when strikes occurred throughout the year, we used a second generalised linear mixed model, using both season and month as the response variables and year fitted as a random effect, and another for time of day. For time of day, light conditions were summarised as 'dawn', 'day', 'dusk' and 'night' whereby a strike which occurred within $60 \mathrm{~min}$ utes either side of sunrise or sunset was categorised as either dawn or dusk respectively. Strikes which occurred more than 60 minutes after sunrise were classified as day and strikes which occurred more than 60 minutes after sunset were classified as night. Model assumptions were checked using the 'DHARMa' package (Hartig 
2019) according to Nakagawa \& Schielzeth (2013). The strength of association between strikes and year of incidence was tested with a Spearman's Rho $(\rho)$.

\section{Results}

\section{Strike numbers}

A total of 320 strike events with hares occurred at Dublin Airport between 1990 and 2019. From carcasses where sex could be identified ( $n=48 \%$ of carcasses), $62 \%$ were male, and $73 \%$ of hares struck were adults. Average carcass weight was $2172 \mathrm{~g} \pm 664$ (mean $\pm \mathrm{SD} ; n=14$; Online Resource 1). Whilst some hare carcasses displayed signs of scavenger interference, no carcass was considered the result of a predator kill (from $n=54$ carcasses). Since 1997, there has been at least one hare strike per year, with a maximum of 44 strike events ( $n=46$ hares) recorded in 2018. There were $10.66 \pm 2.35$ (mean $\pm \mathrm{SE})$ hare strikes per year across all years. Increased numbers of strikes between 2010 and 2019 resulted in a higher mean value of $26.5 \pm 3.16$ strikes per year (Fig. 1). A significant difference between decennial sampling periods was identified $\left(\chi_{(2, N=30)}^{2}=23.8, p<0.01\right)$. Post hoc analyses showed a significant difference between the median strike number for all three sampling periods,

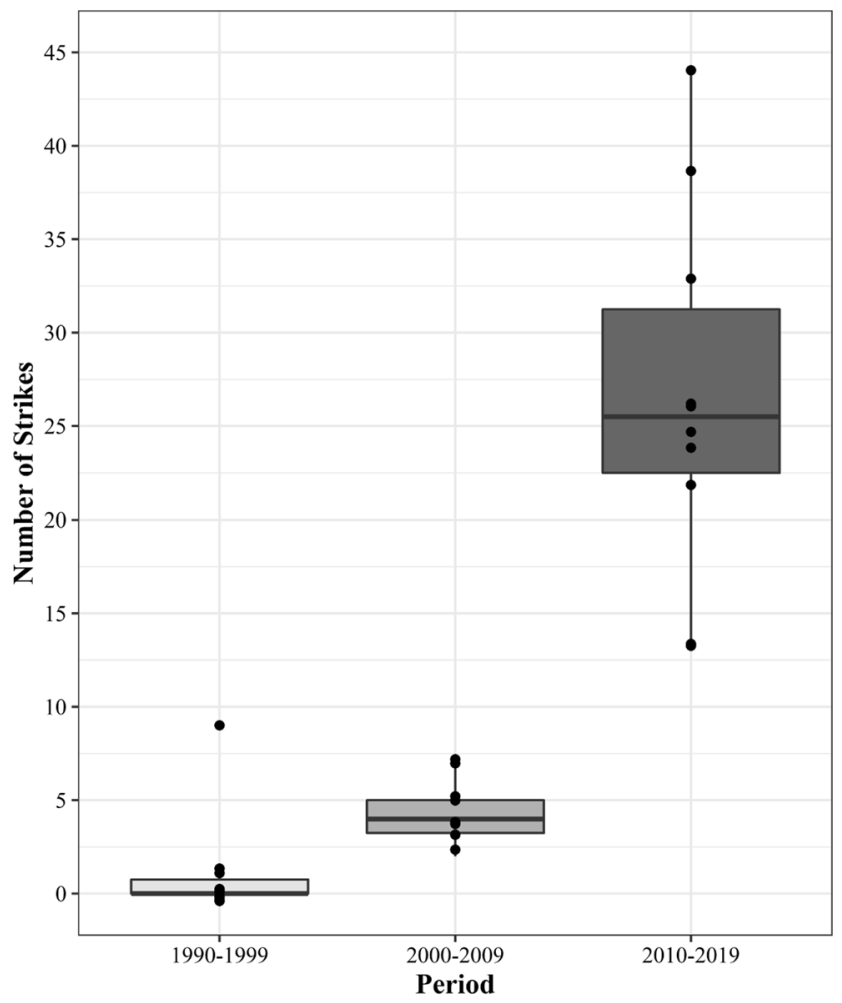

Fig. 1 Left: Irish hare (Lepus timidus hibernicus) strikes at Dublin Airport for each of the three, 10-year study periods. Right: Number of aircraft movements recorded at Dublin Airport for the same three with a median of zero strikes for 1990-1999, five strikes for 2000-2009 and 25.5 strikes for 2009-2019 (Fig. 1). Both dawn (GLMM $\left.y=1.46, \chi^{2}(1,3), p<0.01\right)$ and night (GLMM $\left.y=1.18, \chi^{2}\left({ }_{1,3}\right), p<0.01\right)$ light conditions had significantly higher strikes than other times of day. Since the first strike in 1997, there has been a 14\% (CI 9-16\%) annual increase in strike events with the Irish hare (GLM $y=0.128, \chi^{2}(23,328)$, $p<0.05)$. Lastly, strike events were recorded year-round; whilst the highest proportion of strikes occurred in May (12\%), strike frequency fluctuated across the year without any discernible pattern for month or season (Fig. 2).

\section{Number of hare strikes in relation to aircraft movements}

There were over 5.1 million aircraft movements recorded at Dublin Airport during the study period. Overall, the number of strike events has increased year-on-year at Dublin and the number of aircraft movements has generally increased (Fig. 3). The mean number of hare strikes per 10,000 aircraft movements over the 30 -year study period was $0.55 \pm 0.12$, with a peak in 2018 of 1.89 strikes per 10,000 movements (Fig. 3). In 2011, the number of strike events with hares surpassed one strike per 10,000 aircraft movements and has been sustained above this level for the remainder of the study period, except for 2019 , where 0.54 strikes per 10,000

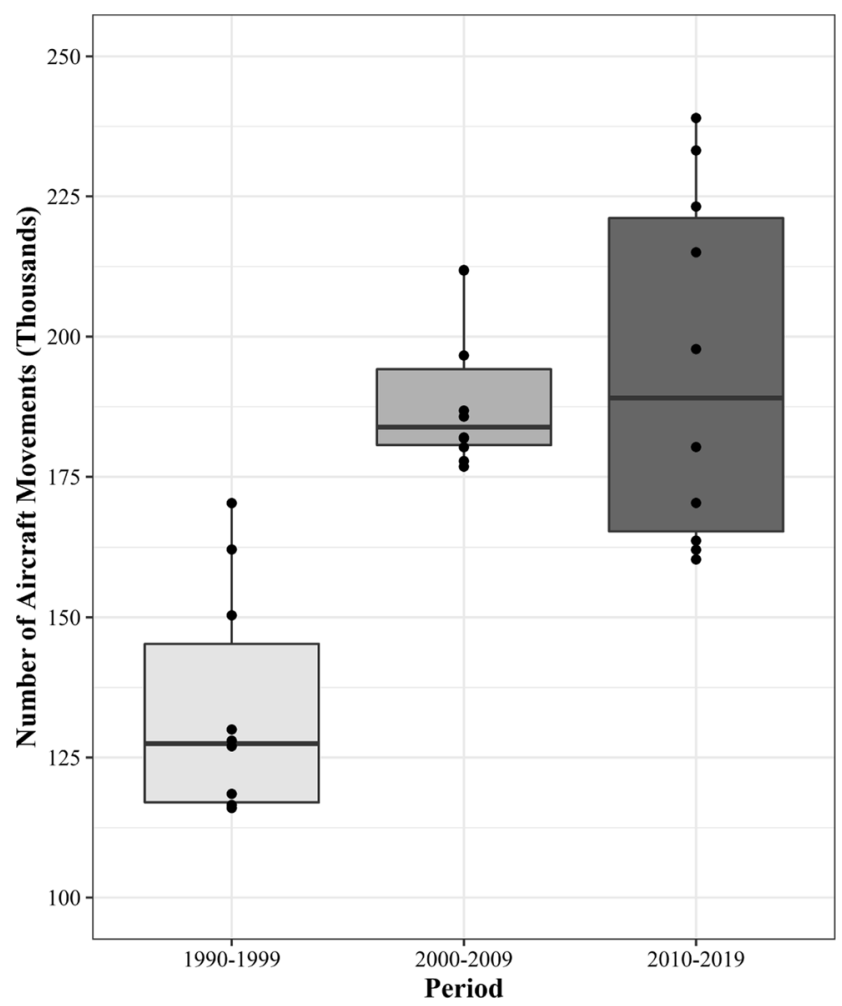

time periods. The median number of events (strikes and aircraft movements) are displayed for each decade. Dots show the spread of the number of events recorded for each year within the decade 
A
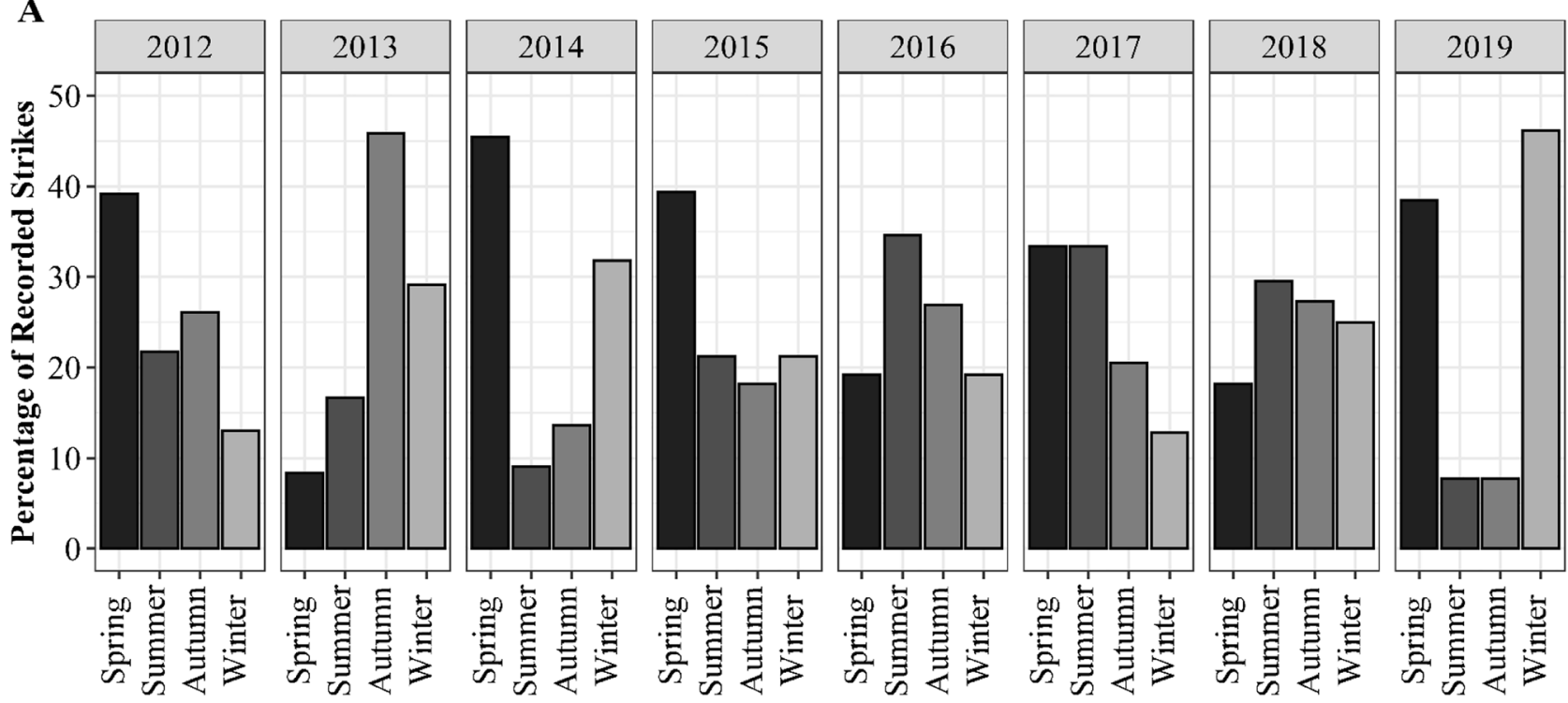

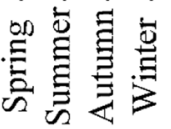
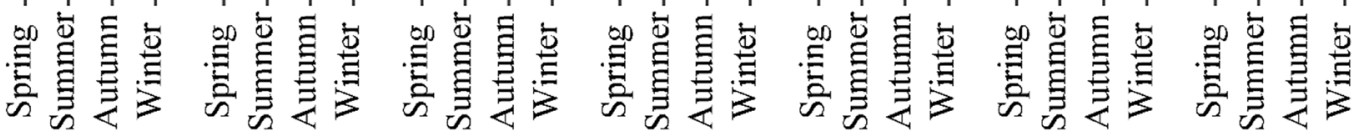

Season

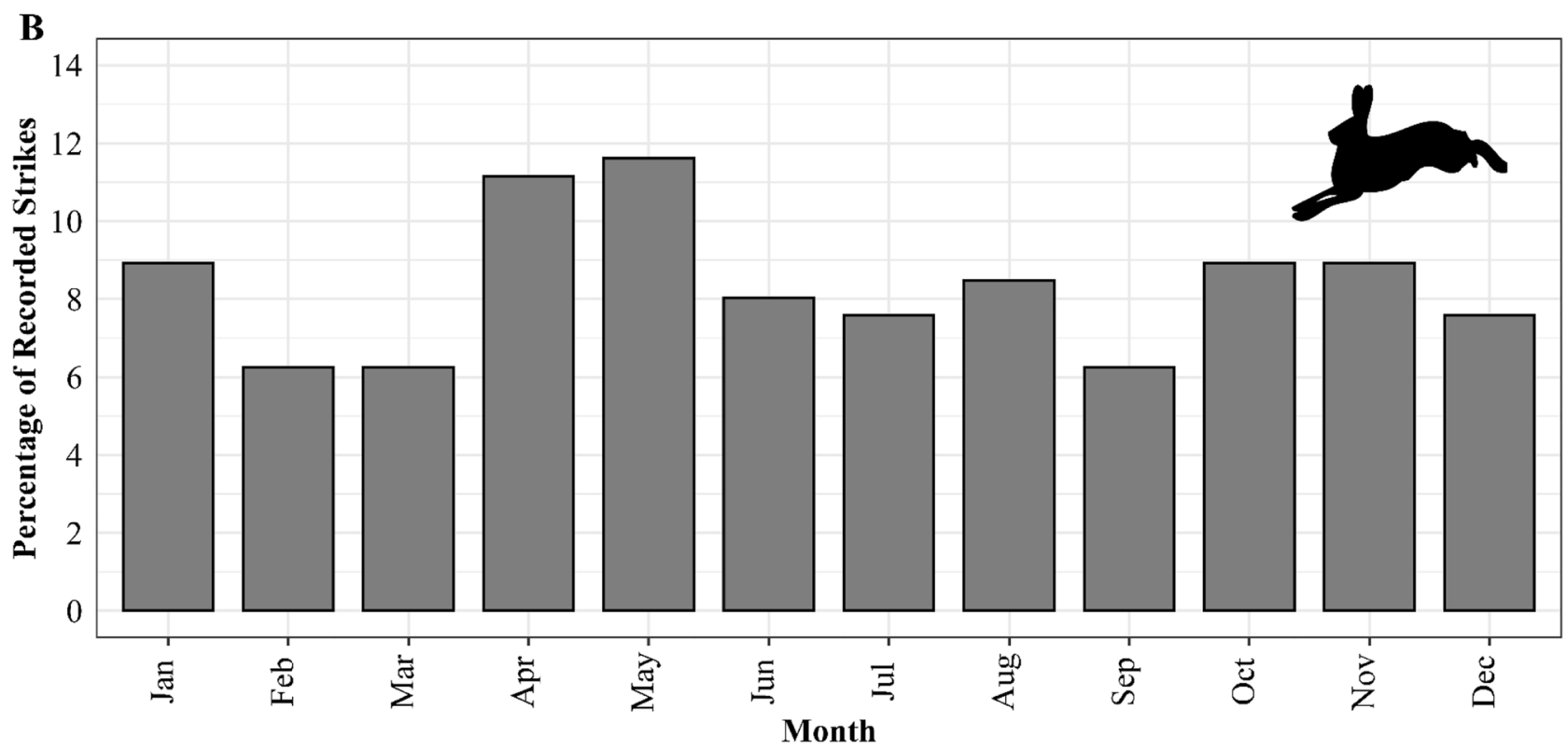

Fig. 2 A Percentage of strike events with the Irish hare (Lepus timidus hibernicus) recorded at Dublin Airport for each season between 2012 and 2019. B Cumulative percentage of all strike events with the

aircraft movements were recorded. This dip corresponded in a reduction in available grassland habitat by approximately 80 ha due to the commencement of construction works for the installation of an additional runway. There was a significant positive association between the number of aircraft movements and the number of recorded hare strike events, across all years (GLMM $y=1.38, \chi^{2}\left({ }_{1,30}\right), p<0.01$, $\rho=0.66)$. However, the number of aircraft movements only explained $57 \%$ of the model variance, indicating that there was a strong temporal influence (year) on the number of recorded strike events, as evidenced in Fig. 3C.
Irish hare recorded for each month at Dublin Airport, between 2012 and $2019(n=224)$. Spring = March-May; Summer $=$ June-August; Autumn $=$ September-November; Winter $=$ December-February

\section{Potential of impact damage}

The potential impact damage caused by a hare strike, to the two civil aircraft types with the greatest number of movements at airfields in the Republic of Ireland is demonstrated in Table 1. The corresponding kinetic energy of $7800 \mathrm{ft}-\mathrm{lbs}$ for the Airbus A320 and $7269 \mathrm{ft}-\mathrm{lbs}$ for the Boeing 737 would likely cause significant metal distortion and/or mechanical damage in the event of an ingestion into the moving parts of an aircraft jet engine (European Aviation Safety Agency 2010; Metz et al. 2021). Whilst this is 


\section{A}
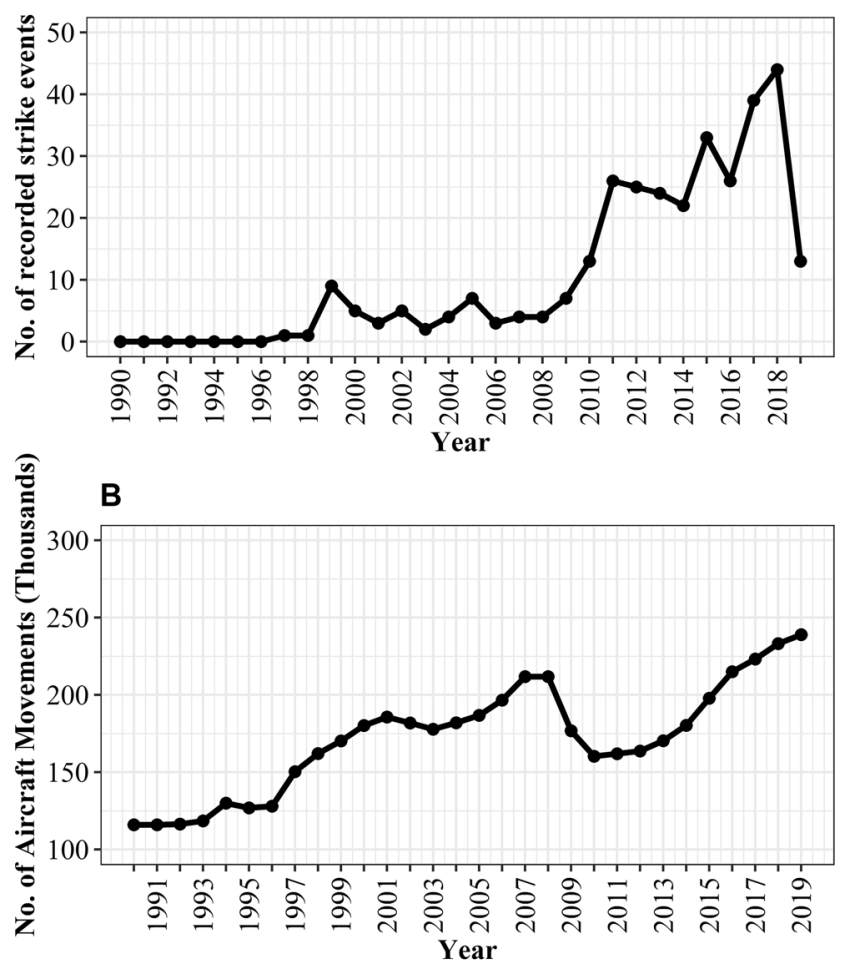

Fig. 3 A Number of recorded strike events with Irish hares (Lepus timidus hibernicus) at Dublin Airport from 1990 to 2019. No strikes were recorded between 1990 and 1996. B Number of aircraft movements (defined as take-off and landing manoeuvres) recorded at Dub-

unlikely, it remains a cause of concern at the airfield, with an isolated incident resulting in the turning around of an aircraft over concerns of an ingestion event. The kinetic energy values obtained for both aircraft types also have the potential to cause significant damage to the landing gear $(\sim 10,000 \mathrm{~J})$ of aircraft that strike hares. Damaged landing gear could not only require airside emergency services to remain on standby at the aircrafts destination but could

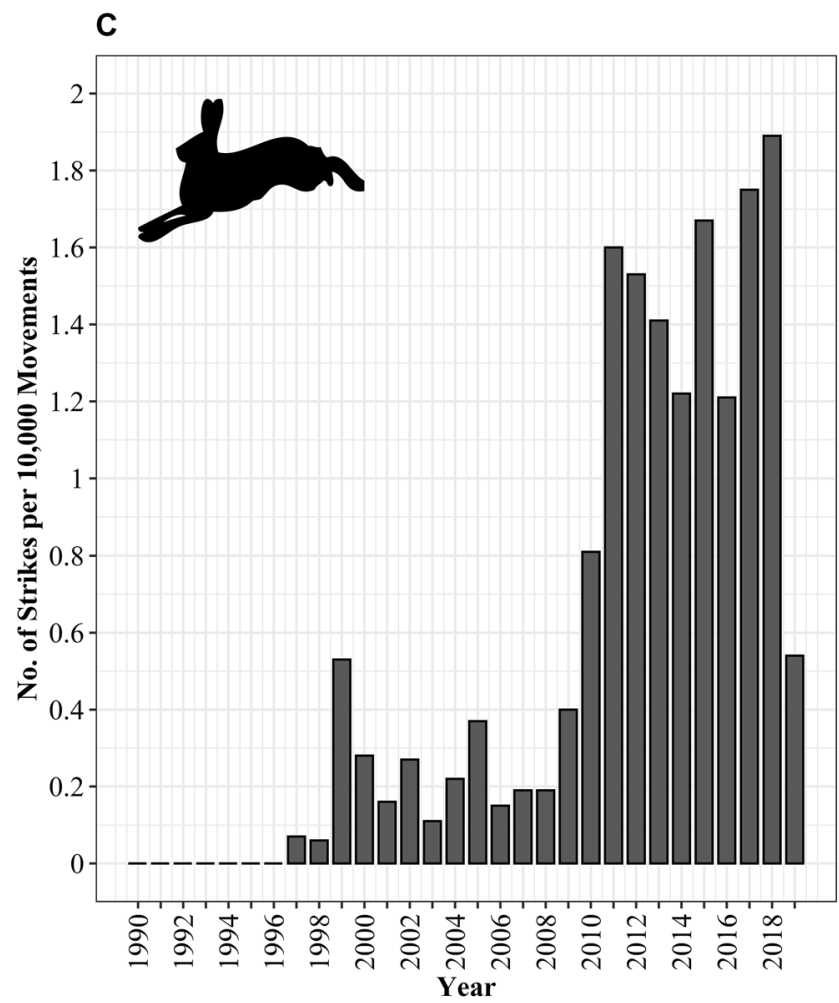

lin Airport between 1990 and 2019. C Number of strike events with Irish hares per 10,000 aircraft movements (take-off and landings) at Dublin Airport

potentially result in runway excursions-something which could be particularly dangerous at high speeds. Additionally, given the mass of a hare $(\leq 3.8 \mathrm{~kg})$, the hitting of FOD on the lower wings or underbelly of the aircraft could cause substantial damage (European Union Aviation Safety Agency Certification 2020), particularly in an event involving a large hare (Fig. 4). Lastly, the kinetic energy values of both the red fox (A320: 26,442 J; B737: 24,638 J) and

Fig. 4 Kinetic energies (Joules and $\mathrm{ft}-\mathrm{lbs}$ ) of collisions between Irish hares (Lepus timidus hibernicus) of low (1.3 kg), medium $(2.2 \mathrm{~kg})$ and high $(3.8 \mathrm{~kg})$ mass with aircraft ranging from 1 to $75 \mathrm{~m} / \mathrm{s}$. Weights were obtained from carcasses previously involved in strike events at Dublin Airport, with the lowest weight recorded from a juvenile and the highest from an adult female

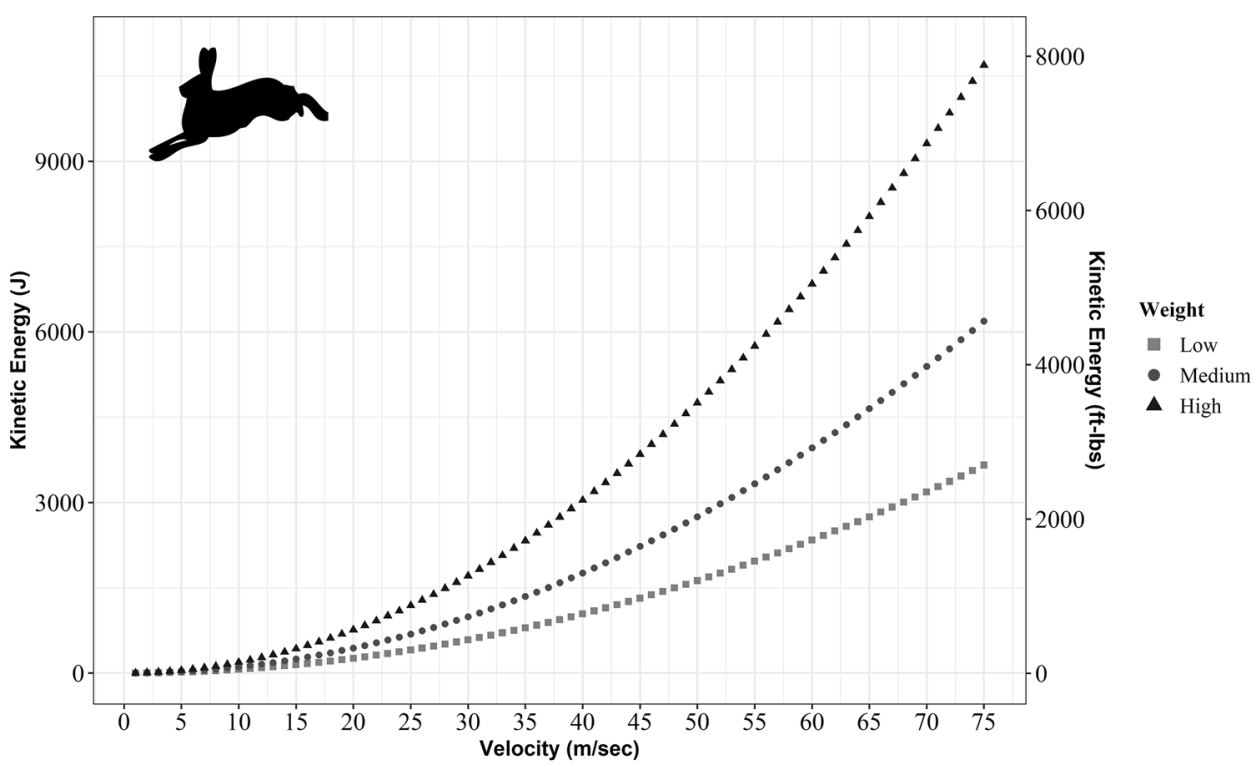


the common buzzard (A320: 3,897 J, B737: 2,874 J) are sufficient to cause significant damage to an aircraft (Dennis et al. 2009).

\section{Discussion}

The number of aircraft movements per annum at Dublin Airport has increased from 116,000 movements in 1990, to almost 249,000 in 2019. The rate of increase has not been constant, with several peaks and troughs over time coinciding with socio-economic and global events, such as the 2008 economic crash, which caused air travel demand to plummet (Franke and John 2011). Further, whilst air traffic is at least partially responsible for strike events, some of the variance observed in annual strike rates could be attributed to fluctuations in the size of the hare population in and around the airfield. We suggest, therefore, that management plans must consider the population ecology of local species involved in strike events if they are to be effective.

Strike events with hares at Dublin Airport have the potential to cause significant damage to an aircraft's engine if ingested or cause severe damage to the landing gear. Equally, the mass of an undetected hare carcass from an earlier strike has the potential to cause significant FOD to an aircraft. Whilst there have been no damaging strike events to date, strike incidents have resulted in the turning around of aircraft. This is particularly concerning given the $14 \%$ annual increase in strike events and the simultaneous increase in the number of strikes per 10,000 aircraft movements from 0.07 in 1997, to a peak of 1.89 in 2018. The noticeable dip in strikes per 10,000 aircraft movements in 2019 is likely to be attributed to the commencement of intensive airside construction works. The overall average strike rate of $0.55 \pm 0.12$ per 10,000 aircraft movements over the 30-year period is relatively low, compared to an average strike rate of $2.89 \pm 0.14$ for birds (Kelly et al. unpublished data). Indeed, Irish hare strikes make up an average of $30 \% \pm 2.71(2010-2018)$ of all wildlife strike events at the airfield and are the only mammal species to regularly be involved in strike events at Dublin Airport. Furthermore, the rejection of take-offs and/or landing windows by pilots due to the presence of hares on a runway can incur additional financial costs and flight delays, as can temporary closure of a runway for decontamination (i.e. removal of the debris field). For example, in the USA, terrestrial mammal strikes are estimated to have caused upwards of $330,500 \mathrm{~h}$ of aircraft downtime (Dolbeer and Begier 2021). Strike events with mammalian species are increasing, with terrestrial mammals, including lagomorphs, having caused substantial damage to aircraft, globally (Dolbeer et al. 2000; Biondi et al. 2011; Crain et al. 2015). The increased hare strike rate per 10,000 movements observed in the present study suggests that strikes will become increasingly common if effective mitigation measures are not implemented, thereby increasing the likelihood of a damage-inflicting event.

Not only are mammals a primary strike threat in themselves, but their presence can introduce secondary strike risk (Pennell et al. 2016) with predatory and scavenger species (Hauptfleisch and Avenant 2015). This is of particular concern at Dublin Airport, where experience has shown that there is a scavenger guild of avian and mammalian taxa present at the airfield. This includes the common buzzard, herring gull (Larus argentatus), lesser black-backed gull (Larus fuscus), greater black-backed gull (Larus marinus), the rook (Corvus frugilegus), hooded crow (Corvus cornix) and the raven (Corvus corax) all of which are $>500 \mathrm{~g}$ in weight, in addition to the red fox. These species-widespread throughout Ireland (Cummins et al. 2019; Lewis et al. 2019)—are frequently encountered at the airfield (Kelly, unpublished data; Online Resource 2), and many have caused significant damage to aircraft over the 1990-2019 interval. These scavengers may have been lured to the airfield by the presence of a hare carcass, or the debris of edible tissues, resulting from an earlier collision. Indeed, the debris from a single strike event has been recorded to cover an area in access of $20 \mathrm{~m}^{2}$ (Bolger and Kelly 2008). Here, we have demonstrated that a secondary strike event with a scavenger could inflict significant damage to an aircraft.

Generally, strike frequency with wildlife is considered to be influenced by local occurrence and abundance of species (Schwarz et al. 2014). However, strike events have been recorded to have occurred for every month of the year at Dublin Airport, and although May had the highest recorded monthly proportion of strikes, events were relatively consistent across months with no distinct seasonal patterns. Further, hares, including the Irish hare, are known to display inter-annual population fluctuations, which can vary substantially within short periods of time (Reynolds et al. 2006; Reid et al. 2007; McGowan et al. 2019). This means that strike events at Dublin cannot be affiliated with a single life history stage or event, adding additional complexity to mitigation measures, as all behaviours and life stages of the species need to be incorporated into wildlife management. For example, mammal strikes have been affiliated with seasonal increases in food availability (e.g. bats; Parsons et al. 2009) and the breeding cycle (e.g. canids; Crain et al. 2015). Accordingly, we suggest that management plans must consider the population ecology of local species involved in strike events if they are to be effective. Indeed, as some particularly fecund taxa, such as leporids (Caravaggi 2018), can require near-continuous management inputs at airfields.

In order to develop targeted and effective strike mitigation, the ecology and behaviours of mammal species using the airfield environment need to be understood and incorporated 
into wildlife hazard management plans. Whilst the translocation of individuals of conservation concern (e.g., Irish hare) to suitable, low-density areas could help to control airside population size whilst aiding national conservation efforts, removal programs on their own may not always be an effective long-term solution due to rapid recolinisation by a species (e.g. Palmas et al. 2020). Therefore, the presence and activity patterns of animals at airfields can be determined through the use of modern, remote monitoring equipment (e.g., camera traps and GPS collars) allowing for the collection of high-quality data in sensitive, airport environments (e.g. Scheideman et al. 2017). Additionally, the maintenance of comprehensive strike data allows for the identification of increased risk both spatially and temporally, which can allow for increased staffing and runway patrols to reduce strikes (Crain et al. 2015). Lastly, a future research priority should be the development of a suitable risk index (e.g. Soldatini et al. 2011) for mammal species at airfields. Combined, such techniques can allow for the implementation of targeted strike mitigation at the individual airport level.

\section{Conclusion}

Strike events with mammal taxa have been recorded to be increasing in several countries globally. Here, we demonstrate that the number of annual strike events involving Irish hares at Ireland's busiest international airport has increased since 1990, with a ten-fold increase between 1998 and 2018. Despite this increase, strikes are of little concern regarding the conservation status of the species. Whilst the number of strike events declined in 2019 possibly due to commencement of construction for an additional runway, it is likely that the strike rate will increase when disturbance has ceased. Not only are hare strike events disruptive and costly to ongoing operations, but an undetected carcass can pose a significant threat to an aircraft as debris or by attracting scavengers. Strike events with lagomorphs are recorded globally; hence, the threat that leporids pose to aircraft safety is not unique to Ireland. Dublin Airport provides a model system to study strike patterns, associated costs and implications, and mitigation measures with leporids. Robust, ecological survey methods utilising modern technology (e.g., camera traps, GPS tracking) need to be implemented at Dublin Airport to better understand hare ecology at the airfield and to inform the development of targeted strike mitigation measures.

Supplementary information The online version contains supplementary material available at https://doi.org/10.1007/s10344-021-01517-y.

Acknowledgements We gratefully acknowledge the contribution of the airfield staff and airport authorities at Dublin Airport for compiling the database upon which this paper is based. This work was conducted as part of a PhD studentship funded by the Irish Research Council (IRC) and the Dublin Airport Authority in collaboration with University College Cork (project EBPPG/2018/43).

Author contribution The lead author (SB) led writing and data analysis for the article. Data were collected and collated for 28 years by TCK and for 2 by RW. All co-authors contributed to editing and approving the manuscript and are listed alphabetically.

Funding Open Access funding provided by the IReL Consortium. This research is funded by the Irish Research Council (IRC) and the Dublin Airport Authority (project: EBPPG/2018/43).

\section{Declarations}

Ethics approval This research has received ethical approval from the University College Cork Animal Experimentation Ethics Committee (AEEC) (\#2019-003).

Consent for publication All parties involved consent to the publication of this work.

Conflict of interest This work was conducted as part of a collaborative $\mathrm{PhD}$ studentship. The lead author (SB) is employed by the Dublin Airport Authority for the purpose of conducting airside research, for the duration of the studentship.

Open Access This article is licensed under a Creative Commons Attribution 4.0 International License, which permits use, sharing, adaptation, distribution and reproduction in any medium or format, as long as you give appropriate credit to the original author(s) and the source, provide a link to the Creative Commons licence, and indicate if changes were made. The images or other third party material in this article are included in the article's Creative Commons licence, unless indicated otherwise in a credit line to the material. If material is not included in the article's Creative Commons licence and your intended use is not permitted by statutory regulation or exceeds the permitted use, you will need to obtain permission directly from the copyright holder. To view a copy of this licence, visit http://creativecommons.org/licenses/by/4.0/.

\section{References}

Allan JR (2002) The costs of bird strikes and bird strike prevention. In: Clark L (ed) Proceedings of the National Wildlife Research Center symposium, human conflicts with wildlife: economic considerations. U.S. Department of Agriculture, National Wildlife Research Center, Fort Collins, Colorado, USA., pp 147-153

ATSB (2019) Australian aviation wildlife strike statistics, 2008-2017. Canberra ACT

Ball S, Caravaggi A, Butler F (2021) Runway roadkill : a global review of mammal strikes with aircraft. Mamm Rev 1-16. https://doi.org/ 10.1111/mam. 12241

Ball S, Thomas T, Butler F (2020) Endoparasites of the endemic Irish hare Lepus timidus hibernicus. Wildlife Biol 3. https://doi.org/ 10.2981/wlb.00717

Bates D, Mächler M, Bolker B, Walker S (2015) Fitting linear mixedeffects models using lme4. J Stat Softw 67:51. https://doi.org/10. 18637/jss.v067.i01

Benjamini Y, Hochberg Y (1995) Controlling the false discovery rate: A practical and powerful approach to multiple testing. J R Stat Soc 57:289-300. https://doi.org/10.1111/j.2517-6161.1995.tb02031.x 
Biondi K, Belant J, Martin J et al (2011) White-tailed deer incidents with U.S. civil aircraft. Wildl Soc Bull 35:303-309. https://doi. org/10.1002/wsb.46

Bolger R, Kelly T (2008) Wildlife Management Plan 2008. Dublin Airport Authority, Dublin, Ireland

Caravaggi A (2018) Lagomorpha life history. In: Vonk J, Shackelford TK (eds) Encyclopedia of Animal Cognition and Behavior, 1st edn. Springer International Publishing, pp 1-9

Caravaggi A, Montgomery I, Reid N (2017) Management and control of invasive brown hares (Lepus europaeus): Contrasting attitudes of selected environmental stakeholders and the wider rural community. Biol Environ 117B. https://doi.org/10.3318/BIOE.2017.08

Crain A, Belant J, DeVault T (2015) Carnivore incidents with U.S. civil aircraft. Transp Res Part D 36:160-166. https://doi.org/10. 1016/j.trd.2014.12.001

Cummins S, Lauder C, Lauder A, Tierney TD (2019) The status of Ireland's breeding seabirds: birds directive article 12 reporting 2013 - 2018. National Parks and Wildlife Service, Department of Culture, Heritage and the Gaeltacht, Ireland, Dublin, Ireland

Dale L (2009) Personal and corporate liability in the aftermath of bird strikes : a costly consideration. Human- Wildl Conflicts 3:216-225

Demongin L (2016) Identification guide to birds in the hand. Cambridge University Press, Cambridge, UK

Dennis L, Lyle D, Budgey R et al (2009) Bird strike damage and windshield bird strike. European Aviation Safety Agency. Final Report, Surrey, UK

Dolbeer R., Begier MJ (2021) Strikes to civil aircraft in the United States, 1990-2019. Federal Aviation Administration. U.S. Department of Agriculture, Animal and Plant Health Inspection Service, Wildlife Services

Dolbeer R, Wright S, Cleary E (2000) Ranking the hazard level of wildlife species to aviation. Wildl Soc Bull 28:372-378. https:// doi.org/10.2307/3783694

European Aviation Safety Agency (2010) Certification specifications for engines. Cologne, Germany

European Union Aviation Safety Agency Certification (2020) Certification specifications and acceptable means of compliance for large aeroplanes

Franke M, John F (2011) What comes next after recession? - Airline industry scenarios and potential end games. J Air Transp Manag 17:19-26. https://doi.org/10.1016/j.jairtraman.2010.10.005

Harris S, Yalden D (2008) Mammals of the British Isles: handbook, 4th revise. Mammal Society, Southampton

Hartig F (2019) DHARMa: residual diagnostics for hierarchical (multilevel/mixed) regression models. $r$ Packag

Hauptfleisch M, Avenant N (2015) Integrating small mammal community variables into aircraft-wildlife collision management plans at Namibian airports. Integr Zool 10:515-530. https://doi.org/10. 1111/1749-4877.12160

House APN, Ring JG, Hill MJ, Shaw PP (2020) Insects and aviation safety: the case of the keyhole wasp Pachodynerus nasidens (Hymenoptera: Vespidae) in Australia. Transp Res Interdiscip Perspect 4:100096. https://doi.org/10.1016/j.trip.2020.100096

IATA (2019) The International Air Transport Association Annual Review. International Air Transport Association, Montréal, Canada

Kelly TC, Coughlan N, Dillane E et al (2016) First record of red grouse Lagopus lagopus scotica killed by aircraft in Ireland and Britain. Irish Birds 10:440-442. https://doi.org/10.1098/rsbl.2016.0362.Waite

Kelly TC, Sleeman P, Coughlan NE et al (2017) Bat collisions with civil aircraft in the Republic of Ireland over a decade suggest negligible impact on aviation safety. Eur J Wildl Res 63:23-26. https://doi.org/10.1007/s10344-017-1081-x

Kitowski I (2016) The impact on aviation operations at Polish civil airfields caused by mammals. Bezpieczeństwo i Tech Pożarnicza 42:57-63. https://doi.org/10.12845/bitp.42.2.2016.5
Lewis L, Coombes D, Burke B et al (2019) Countryside bird survey: status and trends of common and widespread breeding birds 1998-2016. National Parks and Wildlife Service, Department of Culture, Heritage and the Gaeltacht, Ireland, Dublin, Ireland

McGowan NE, McDermott N, Stone R et al (2019) National Hare Survey and Population Assessment 2017-2019. Dublin, Ireland

McKee J, Shaw P, Dekker A, Patrick K (2016) Approaches to wildlife management in aviation. In: Angelici FM (ed) Problematic wildlife: a cross-disciplinary approach. Springer International Publishing Switzerland, pp 1-603

Mendonca F, Keller J, Wang Y (2017) Managing the risks : an analysis of bird strike reporting at Part 139 airports in Indiana 2001-2014. J Airl Airpt Manag 7:43-64. https://doi.org/10.3926/jairm.82

Metz IC, Ellerbroek J, Mühlhausen T et al (2020) The bird strike challenge. Aerospace 7:1-20. https://doi.org/10.3390/aerospace7030026

Metz IC, Ellerbroek J, Mühlhausen T et al (2021) Analysis of riskbased operational bird strike prevention. Aerospace 8:1-22. https://doi.org/10.3390/aerospace8020032

Nakagawa S, Schielzeth H (2013) A general and simple method for obtaining R2 from generalized linear mixed-effects models. Methods Ecol Evol 4:133-142. https://doi.org/10.1111/j.2041-210x. 2012.00261.x

Noaves W, Grossmann N, Pimentel D, Prada M (2016) Terrestrial mammal and reptile hazards in an airport in the Brazilian Amazon. Human-Wildlife Interact 10:122-127

Palmas P, Gouyet R, Oedin M et al (2020) Rapid recolonisation of feral cats following intensive culling in a semi-isolated context. NeoBiota 63:177-200. https://doi.org/10.3897/neobiota.63.58005

Parsons J, Blair D, Luly J, Robson S (2009) Bat strikes in the Australian aviation industry. J Wildl Manage 73:526-529. https://doi.org/10. 2193/2008-268

Pennell C, Rolston MP, Latham AD et al (2016) Novel grass-endophyte associations reduce the feeding behaviour of invasive European rabbits (Oryctolagus cuniculus). Wildl Res 43:681-690. https:// doi.org/10.1071/WR16114

Reid N, Dingerkus K, Montgomery WI et al (2007) Status of hares in Ireland. Irish Wildlife Manuals, No. 30. National Parks and Wildlife Service

Reid N, McDonald RA, Montgomery WI (2010) Homogeneous habitat can meet the discrete and varied resource requirements of hares but may set an ecological trap. Biol Conserv 143:1701-1706. https://doi.org/10.1016/j.biocon.2010.03.041

Reynolds JC, O'Mahony D, Aebischer NJ (2006) Implications of "cyclical" population dynamics for the conservation of Irish hares (Lepus timidus hibernicus). J Zool 270:408-413. https://doi.org/ 10.1111/j.1469-7998.2006.00147.x

Scheideman M, Rea R, Hesse G et al (2017) Use of wildlife camera traps to aid in wildlife management planning at airports. J Airpt Manag 11:408-419

Schwarz K, Belant J, Martin J et al (2014) Behavioral traits and airport type affect mammal incidents with U.S. civil aircraft. Environ Manage 54:908-918. https://doi.org/10.1007/s00267-014-0345-4

Soldatini C, Albores-Barajas Y, Lovato T et al (2011) Wildlife strike risk assessment in several Italian airports : lessons from BRI and a new methodology implementation. PLoS One 6:p.e28920. https:// doi.org/10.1371/journal.pone.0028920

UKCAA Safety Regulation Group CAP (2008) CAP 772 Birdstrike risk management for aerodromes. London, UK

Washburn B, Seamans T (2013) Managing turfgrass to reduce wildlife hazards at airports. In: DeVault T, Blackwell B, Belant J (eds) Wildlife in airport environments: preventing animal-aircraft collisions through science-based management. Johns Hopkins University Press, Baltimore, Maryland, pp 105-114

Publisher's Note Springer Nature remains neutral with regard to jurisdictional claims in published maps and institutional affiliations. 